\title{
A Nationwide Survey of Shift Schedules for Sleep Technicians in Korea
}

\author{
Seo-Young Lee ${ }^{1}$, Su Jung Choi ${ }^{2}$, Sooyeon Suh ${ }^{3}$, Pamela Song ${ }^{4}$, Eun Yeon Joo ; Shift Work Disorder Study Group \\ ${ }^{1}$ Department of Neurology, Kangwon National University School of Medicine, Chuncheon, \\ ${ }^{2}$ Department of Nursing, Samsung Medical Center, Department of Clinical Nursing Science, Graduate School of Clinical Nursing Science, \\ Sungkyunkwan University, Seoul, \\ ${ }^{3}$ Department of Psychology, Sungshin Women's University, Seoul, \\ ${ }^{4}$ Department of Neurology, Inje University College of Medicine, Ilsan Paik Hospital, Goyang, \\ ${ }^{5}$ Department of Neurology, Neuroscience Center, Samsung Medical Center, Sungkyunkwan University School of Medicine, Seoul, Korea
}

\section{국내 수면검사실 근무자들의 교대근무 현황}

이서영 ${ }^{1}$, 최수정 ${ }^{2}$, 서수연 ${ }^{3}$, 송파멜라 ${ }^{4}$, 주은연 ${ }^{5}$; 교대근무연구회

강원대학교 의학전문대학원 신경과학교실, ${ }^{1}$ 성균관대학교 임상간호대학원 삼성서울병원 간호부, ${ }^{2}$ 성신여자대학교 심리학과, ${ }^{3}$

인제대학교 의과대학 일산백병원 신경과, ${ }^{4}$ 성균관대학교 의과대학 삼성서울병원 신경과학센터 신경과학교실 ${ }^{5}$

Received May 30, 2018

Revised June 12, 2018

Accepted June 15, 2018

Address for correspondence Eun Yeon Joo, MD, PhD

Sleep Medicine and

Chronobiology Laboratory,

Department of Neurology,

Samsung Medical Center,

Neuroscience Center,

Samsung Biomedical

Research Institute,

Sungkyunkwan University

School of Medicine,

81 Irwon-ro, Gangnam-gu,

Seoul 06351, Korea

Tel: $+82-2-3410-1368$

Fax: +82-2-3410-0052

E-mail: ejoo@skku.edu
Objectives: It is a paradox that sleep technicians are at risk of shift work sleep disorder to help diagnose other people's sleep disorder. Until now, there have been no guidelines for scheduling shifts for sleep technicians. The purpose of this study was to survey the current shift schedule of sleep technicians. Methods: We performed a nationwide survey of work schedules for sleep laboratories. We sent email questionnaires to sleep technicians working in university-affiliated hospitals. Information regarding starting time and duration of shift, duty on- duty off pattern for the past month, and rotation and number of sleep technicians in the sleep labs were collected. Results: We received responses from 29 sleep labs. Among the 25 labs which had designated sleep technicians, three labs had night shift schedules mixed with day work on a weekly basis and the remaining 22 labs had night only shift schedule. In cases of night only shift schedules, 11 labs alternated from night shift to day shift works or vice versa every 3 months to 3 years, while the remaining 11 labs had fixed schedules without daytime rotation. Number of night shift was four or less per week, with shift durations of 9-19 hours. Conclusions: The current policies regarding scheduling shifts varied vastly depending on individual sleep labs. We found that some labs had shift schedules with long work time, quick returns, or permanent night shifts, which are generally not recommended. Further studies are needed to develop consensus guidelines for scheduling shift of sleep technicians.

J Sleep Med 2018;15(1):15-19

\begin{abstract}
서 론
수면검사실 근무자는 환자들의 수면을 검사하거나 치료하 기 위해 본인은 밤에 일하는 특수한 직업 환경에 처해 있다. 야간 근무자는 일반적으로 일주기리듬과 불일치하는 생활을 해야 하므로, 가정 및 사회생활에 어려움을 겪는다. ${ }^{1}$ 또한 일

This is an Open Access article distributed under the terms of the Creative Commons Attribution Non-Commercial License (https://creativecommons.org/licenses/by-nc/4.0) which permits unrestricted non-commercial use, distribution, and reproduction in any medium, provided the original work is properly cited.
\end{abstract}

주기리듬의 교란은 수면 부족을 흔히 유발하여, 근무 중 또 는 휴식기에 인지기능 저하나 피로를 가져오기 쉽다. 뿐만 아니라 수면 부족이 사고나 여러 만성질환의 위험을 높인다 는 증거들이 축적되고 있다. ${ }^{2}$ 따라서 교대근무자의 수면이나 건강에 대해서 관심이 높아지고 있으며, 이를 고려한 교대근 무 일정에 대한 권고들이 있었다. 전진적 교대(forward rotation)-예를 들어 아침 근무, 오후 근무, 밤 근무의 순서로 교대 함, 11 시간 이상의 회복 시간, 12 시간 이내의 근무 시간을 준 수하고, 영속적 야간 근무는 가능하면 피할 것 등이 일반적 
인 지침이나, ${ }^{3-5}$ 업무의 성격이나 강도에 따라 직종별 개별적 인 접근이 필요하다. 간호사, ${ }^{6}$ 응급구조사 등 보건의료 종사 자를 포함한 다양한 교대근무자에 대한 연구도 되어 왔으 나, ${ }^{7,8}$ 수면검사실 근무자에 대한 연구나 수면검사실 근무 일 정에 대한 지침은 아직까지 희박하다.

국내에 수면검사실이 점차 증가하고 있으며, 국민건강보 험 적용으로 수면검사의 양이 급속도로 증가할 것으로 보인 다. 이러한 시점에 수면검사실의 적절한 교대근무 일정이 무 엇인가는 중요한 이슈이다. 이 연구의 목표는 전국 수면검사 실의 근무 현황을 파악하여, 향후 수면검사실 근무자의 일정 을 위한 권고안 수립의 기초 자료를 얻는 것이다.

\section{방 법}

이 연구는 전국의 수면검사실을 대상으로 하였고, 수면검 사실과 운영자의 목록은 대한수면연구학회로부터 제공받았 다. 연구자들은 우선 수면검사실의 운영자를 접촉하여 연구 에 대해 설명하고 근무 일정의 개요와 검사실 근무자의 연락 정보를 받았다. 이후 각 수면검사실 근무자에게 근무 일정에 대한 설문을 이메일로 발송하여 응답을 받았다. 설문은 수면 검사 전담 여부, 수면검사 전담 근무자 수, 최근 1 개월간의 원 칙적 근무 일정, 주간 근무와의 순환(rotation) 여부 및 주기, 근무의 시작과 끝 시간, 근무 횟수에 대한 질문을 포함하였다.

일주일 이내에 다른 형태의 근무가 섞여 있는 경우를 빠른 순환 근무(rapid rotating shift), 순환 주기가 일주일 이상인 경우를 느린 순환 근무(slow rotating shift)로 분류하였다. ${ }^{5}$ 근 무 일정은 수면검사 전담 또는 전담에 준하는 근무자가 있는 기관에 대해 각 검사실에 따라 분석하였다. 이 연구는 기관윤
리위원회의 승인을 받았다(KNUH-2017-05-008-001).

\section{결 과}

대한수면연구학회에 등록된 수면검사실은 45개였으며, 이 중 29개 기관의 46명의 수면검사실 근무자에서 응답을 받았 다. 조사에 응한 검사실은 모두 대학병원에 소속되어 있었고, 신경과에서 운영하고 있거나 또는 신경과를 포함한 여러 과 에서 공동으로 운영하는 검사실이었다. 모두 뇌파, 근전도 등 모든 센서를 부착하고 수면검사실 직원이 밤을 새면서 검사 하는 Type 1 수면다원검사를 시행하는 검사실이었다.

\section{수면검사실 인력}

수면검사만 전담하는 근무자가 있는 기관은 18 곳이었고, 수면검사가 주 업무인 근무자가 일부 다른 신경생리검사를 겸하는 검사실이 7곳, 그리고 신경생리검사실 근무자가 주 1 회 또는 검사가 있을 때 비정기적으로 수면검사를 하는 검사 실이 4곳이었다. 수면검사를 전담하거나 주로 하는 근무자의 수는 12 검사실에서는 한 명, 10 곳은 두 명, 1 곳은 세 명, 2곳 에서는 다섯 명이었다(Table 1).

\section{수면검사실 근무 일정}

수면검사를 전담 또는 주로 하는 근무자가 있는 25 검사실 중, 야간 근무만을 하는 곳이 22곳이었고, 한 주 안에 야간과 주간 근무를 교대하는 경우는 3곳이었다.

모든 기관의 가장 흔한 근무 일정은 야간 근무 사이에 하 루 이상의 휴무 또는 주간 근무를 두는 격일 야간 근무제 (night-off-night-off)로, 이를 채택한 기관이 22개였고, 세

Table 1. Role and number of sleep technicians in each sleep laboratory

\begin{tabular}{|c|c|c|}
\hline Role of sleep technicians & Number of technician & Number of sleep labs \\
\hline \multirow[t]{5}{*}{ Sleep study is their exclusive job } & & 18 \\
\hline & 1 person & 7 \\
\hline & 2 persons & 8 \\
\hline & 3 persons & 1 \\
\hline & 5 persons & 2 \\
\hline Sleep study is their main job & & 7 \\
\hline \multirow[t]{2}{*}{ (they occasionally work for other neurophysiologic studies) } & 1 person & 5 \\
\hline & 2 persons & 2 \\
\hline \multirow[t]{4}{*}{ Sleep study is a part of their job } & & 4 \\
\hline & 1 person & 2 \\
\hline & 2 persons & 1 \\
\hline & 3 persons & 1 \\
\hline Total & & 29 \\
\hline
\end{tabular}


Lee SY et al.

Table 2. Different shift schedule for sleep technicians

\begin{tabular}{lc}
\hline \multicolumn{1}{c}{ Shift schedule for sleep technicians } & Number of sleep labs \\
\hline Rapid rotating shift: mixed day and night shift schedule in a week & 3 \\
Slow rotating shift: rotation from night to day shift & 4 \\
Rotation schedule of 3 moths night shift and 3 months day shift & 2 \\
Rotation schedule of 6 moths night shift and 6 or more months day shift & 4 \\
Rotation schedule of 1 year night shift and 1 year or more of day shift & 1 \\
Rotation schedule of 3 years night shift and 1 year day shift & 11 \\
Permanent night shift & 25 \\
Total number of sleep labs which sleep technician work exclusively, or mainly for sleep studies & \\
\hline
\end{tabular}

기관에서는 2일 연속 야간 근무(night-night)를 하는 일정으 로 운영하고 있었다. 연속 야간 근무를 하는 기관 중, 두 개의 기관은 연속 야간 근무 후 연속 휴일 또는 주간 근무(nightnight-off-off or day)를 하는 일정을 취하였고, 한 기관에서 는 연속 밤 근무를 하면서 주 4회 이상 밤 근무(night-nightoff-night-night)를 하였다. 세 기관의 연속 야간 근무 사이 의 쉬는 시간은 7시간, 9 시간, 13 시간이었다. 3 일 이상 연속 야간 근무를 하는 기관은 없었다.

\section{주간 및 야간 근무의 순환}

야간 근무만 있는 22 검사실 중 11 곳에서는 주간 근무를 주로 하는 업무와의 순환 근무(slow rotating shift) 정책을 갖 고 있었다. 그중 10 개 기관에서 야간 근무 일정의 기간은 3 개 월에서 1년이었고, 주간 근무 일정 동안은 뇌파검사 등 다른 신경생리검사를 하고 있었다. 다른 한 기관에서는 수면검사 실 근무자 중 4명이 돌아가면서 3년은 야간 근무를 하고 1년 동안은 수면다원검사 판독 등 수면검사실 내 주간 업무를 전 담하기로 최근 결정하였다. 주간 근무와의 교대 또는 순환 계 획이 없이 지속적으로 야간 근무만을 하는(permanent night shift) 검사실은 11 곳이었다. 한 주 안에 주간 및 야간 근무를 섞어 하는(rapid rotating shift) 세 곳은, 주간 근무를 주로 하 는 업무와의 순환 계획은 갖고 있지 않았다(Table 2).

\section{근무 시간과 횟수}

전담 및 준-전담 수면검사 직원이 있는 25 기관의 야간 근 무의 시작 시각은 14:00 20:00시, 종료 시각은 7:00 9:00시 였다. 하루 야간 근무 시간은 9시간에서 19시간(평균=14.7, 표준 편차=1.81)이었고, 한 곳을 제외하고 모두(96\%) 12시간 을 초과하였다. 주당 근무 횟수(주간과 야간 포함 출근 횟수) 는 2.5 회에서 5 회로, 주 3 회 근무가 20 기관으로 가장 많았다. 주당 야간 근무 횟수는 2 4회였고, 주당 야간 근무 3 회가 18 기관으로 가장 흔했다. 주당 총 근무 시간은 39시간에서 60시 간 (평균 $=46.01$, 표준 편차 $=5.55$ )이었다.

\section{고 찰}

국내 수면검사실의 근무 형태는 병원별로 매우 다양했다. 수면검사실은 기관의 규모 및 검사 건수에 따라, 뇌파검사 등 을 시행하는 신경계 검사실과 인력을 공유하거나 교대하여 운 영되고 있었다. 근무 일정은 고정적 야간 근무가 11 곳(44\%), 3 개월 이상의 주기로 주야간을 순환하는 '느린 교대근무'가 11 곳(44\%), 일주일 내에 주야간을 교대하는 '빠른 교대근무'가 3 곳 $(12 \%)$ 이었다. 병원 내 타 직종의 근무자들에 비해, 대체 로 일 회당 근무 시간이 길고 근무 횟수는 적었다.

이번 조사는 수면연구학회에서 검사실 목록을 제공받아 신경과에서 운영하는 수면검사실이 주로 대상이 되었기 때 문에, 다른 신경계 검사실과 인력을 공유하는 경우가 많게 나 온 것으로 추정한다. 이는 검사 건수가 적은 기관에서 검사실 을 운영하는 전략이기도 하고, 주간 근무와 교대하는 근무 일 정을 갖기에 유리한 측면도 있다.

대부분은 격일 근무제(night-off-night-off)를 하고 있었지 만, 일부 기관에서는 연속 야간 근무 후 연속 휴일(nightnight-off-off) 또는 주간 근무(night-night-off- day)를 하 고 있었다. 격일 근무제는 야간 근무 후 회복 기간이 길다는 장점이 있지만, 낮에 자고 밤에 깨어 있는 일주기리듬을 계 속 유지해야 하거나 아니면 하루 간격으로 일주기리듬을 바 꿔야 한다. 연속 야간 근무 후 연속 휴일 또는 주간 근무 형 태는 한 주 안에서도 낮에 깨어 있고 밤에 자는 정상적인 일 주기리듬을 연속으로 가질 수 있다는 장점이 있다. 미국의 수면검사실에서는 3 4일 연속 야간 근무를 하고 이후 연속 으로 휴일을 갖는 일정도 흔하다고 한다(개인적 소통). 그러 나, 수면검사실의 야간 근무는 일반 주간 근무자에 비해 대 체로 회당 근무 시간이 길고 야간 근무 후 주간에 바로 잠이 들기 어려울 수 있기 때문에, 연속 야간 근무를 할 경우 근무 사이에 충분한 휴식 시간을 가질 수 있도록 일정을 편성해야 한다. 근무 간 회복 시간은 11 시간 이상을 두는 것이 추천되 고 있으나, ${ }^{3,4}$ 이번에 조사한 검사실 중 두 곳은 근무 간 회복 
시간이 권고보다 짧았다. 12 시간 야간 근무의 경우 연속 근 무는 세 번 이하를 권장하고 있으며, ${ }^{9}$ 이 기준은 모든 검사실 에서 충족하였다.

야간 근무를 해야 하는 직종에서 주간 근무와 교대를 하는 것이 좋은지 고정적으로 야간 근무를 하는 것이 좋은지는 논 란이 있어 왔다.,10-13 작업 수행의 효율이나 근무 중 각성도 는 고정적 야간 근무에서 높은 수준을 보였다. 513 평균 수면 시간이나 수면의 질에 있어서는 연구마다 조금씩 다른 결과 를 보였지만, 고정적 야간 근무자가 순환 근무자에 비해 대 체로 나쁘지 않았다. 13,14 근무 형태에 대한 만족도는 고정적 야간 근무자에서 순환 근무자에 비해 높게 보고되기도 하였 다. ${ }^{15,16}$ 그러나, 고정적 야간 근무자군에서 순환 근무자군에 비해 스스로 근무 형태를 선택한 사람의 비율이 높았고, 봉 급을 포함한 대우가 좋은 경우가 많았음을 고려해야 한다. ${ }^{16}$ 일주기리듬의 면에서는 빛과 어두움을 잘 통제한다면 고정 적인 일정이 유리할 수 있다. ${ }^{10,12}$ 그러나 휴일 동안 사회적 접 촉을 하게 되므로, 야간에 깨어 있고 주간에 자는 일정을 고정 적으로 유지하는 것은 현실적으로 어렵고, 고정적 야간 근무 를 하더라도 일주기리듬의 완전한 적응은 잘 이루어지지 않 는다. ${ }^{17}$ 사회적 측면에서는, 육아 및 학업을 겸할 경우 한시적 으로 긍정적일 수 있지만, 장기간 고정적 야간 근무의 경우는 사회 생활에 부정적인 영향을 줄 가능성이 높다. 종합적으로, 영속적 야간 근무는 가능한 피해야 할 근무 형태로 알려져 있으나, ${ }^{4,5}$ 많은 수면검사실에서 주간 근무와의 순환에 대한 정책을 갖고 있지 않았다. 야간 근무가 핵심인 수면검사실 내에서 주간과 야간을 교대 또는 순환 근무를 하도록 일정을 짜는 것은 쉽지 않다. 국내 일부 기관이 채택한 방식과 같이, 주간 근무를 하는 신경계 검사실의 인력과 순환 근무를 하는 것이 대안이 될 수 있다. 또한 미국의 일부 수면검사실과 같 이 야간 근무만 하더라도 긴 연속 휴일을 보장하는 것이 사 회적 비동기화(social desynchronization)의 부분적 보완책이 될 수 있다.

주간 및 야간 근무의 교대 또는 순환의 주기는 같은 시간 대의 근무를 세 번 이하로 하는 빠른 교대를 하는 근로자에 서 일주일 이상 같은 시간대 근무를 한 후 다른 시간대 근무 로 바꾸는 느린 교대를 하는 근로자보다 일주기리듬 및 수면 장애가 적었고, 규칙적인 사회적 접촉도 가능하다. ${ }^{3,5}$ 그러나, 2주 이상의 간격을 두어 교대하고 중간에 휴일을 두어 일주 기리듬을 서서히 적응하도록 권장하기도 한다. ${ }^{12}$ 영국 보건안 전청에서는 2 3일마다 교대하는 일정을 추천하고 있고, 이 것이 어려울 경우 3 주 이상의 기간을 두고 교대하는 일정을 추천하고 있다. ${ }^{4}$

근무 시간과 횟수에 관해서는, 교대근무자의 경우 일 회당
근무 시간을 길게 하고 대신 근무 횟수를 적게 하는 "압축 근무 주간(compressed work week)"이 직업-생활 균형(work-life balance)을 향상시키는 것이 보고되었다..$^{8}$ 근무 시간 8 시간 과 12 시간을 비교했을 때, 근무자들의 수면과 각성 정도의 차이가 유의하지 않았다. ${ }^{8}$ 본 조사 대상의 $96 \%$ 에서 야간 근 무 시간이 회당 12 시간을 초과하였고, 보건 의료 직종에서 12 시간을 초과하여 근무하는 경우가 간혹 있는데, 12 시간 이상 의 장시간 근무에 대해서는 피로 축적이나 업무 효율 감소의 문제가 평가가 잘 이루어지지 않았다. 근무의 성격, 강도, 근 무 중간에 휴식 가능 여부에 따라 다를 수 있으나, 12 시간 이 상의 근무는 일반적으로 권장되지 않는다. ${ }^{4}$

이 연구는 전국적인 조사이지만 신경과 의사들이 회원의 대부분인 수면연구학회의 협조를 받아 이루어져서, 정신과, 이비인후과나 내과 등에서 주도하거나 개인 의원에서 운영 하는 수면검사실은 조사하지 못했다. 이 때문에 주간에 다른 신경생리검사를 같이하거나 주간 근무와의 순환이 있는 근 무 형태의 비율이 실제보다 높게 평가되었을 가능성이 있다. 또한 근무 형태에 따른 근무자들의 선호도나 근무자에게 미 치는 영향은 조사하지 않아, 이 연구의 결과만으로 어떠한 근무 일정이 더 낫다고 제안할 수는 없다. 그러나, 저자들이 아는 한 본 연구는 수면검사실의 근무 실태에 대한 최초의 학술 보고로서, 수면검사실 근무 형태에 대해 문제를 제기하 여 이후 수면검사실의 적절한 근무 형태를 도출하기 위한 첫 걸음이 될 것이다.

본 조사를 통해, 국내 수면검사실들의 근무 형태가 기관마 다 다양하며 선행 연구를 바탕으로 한 교대근무를 위한 일반 적 권고와는 다른 요소들이 파악되었다. 향후, 근무 일정이 개인의 삶, 건강이나 업무 효율에 미치는 영향에 대한 조사 를 바탕으로 수면검사실 근무 일정에 대한 지침을 마련하는 것이 필요하다.

\section{Acknowledgments}

This research was supported by Basic Science Research Program through the National Research Foundation of Korea funded by the Ministry of Science, ICT \& Future Planning, Republic of Korea (2017R1A2B4003120) and by Samsung Biomedical Research Institute grant (SMX1170571).

\section{REFERENCES}

1. Vogel M, Braungardt T, Meyer W, Schneider W. The effects of shift work on physical and mental health. J Neural Transm (Vienna) 2012;119: 1121-1132.

2. Consensus Conference Panel, Watson NF, Badr MS, et al. Joint consensus statement of the American Academy of Sleep Medicine and Sleep Research Society on the recommended amount of sleep for a healthy adult: methodology and discussion. Sleep 2015;38:1161-1183.

3. Kecklund G, Axelsson J. Health consequences of shift work and insufficient sleep. BMJ 2016;355:15210.

4. Health and Safety Executive. Managing shiftwork: health and safety 
guidance. Liverpool: Health and Safety Executive, 2006.

5. Knauth P. Designing better shift systems. Appl Ergon 1996;27:39-44.

6. Choi SJ, Joo EY. Light exposure and sleep-wake pattern in rapidly rotating shift nurses. J Sleep Med 2016;13:8-14.

7. Sofianopoulos S, Williams B, Archer F. Paramedics and the effects of shift work on sleep: a literature review. Emerg Med J 2012;29:152-155.

8. Driscoll TR, Grunstein RR, Rogers NL. A systematic review of the neurobehavioural and physiological effects of shiftwork systems. Sleep Med Rev 2007;11:179-194.

9. O'Brien R. Five rules for scheduling 12-hour night shifts. Nurs Manage 2015;46:12-13.

10. Wilkinson RT. How fast should the night shift rotate? Ergonomics 1992; 35:1425-1446.

11. Folkard S. Is there a 'best compromise' shift system? Ergonomics 1992; 35:1453-1463; discussion 1465-1466.

12. Eastman CI. How to reduce circadian misalignment in rotating shift workers. ChronoPhysiology and Therapy 2016;6:41-46.

13. Sallinen M, Kecklund G. Shift work, sleep, and sleepiness - differences between shift schedules and systems. Scand J Work Environ Health 2010;36:121-133.

14. Pilcher JJ, Lambert BJ, Huffcutt AI. Differential effects of permanent and rotating shifts on self-report sleep length: a meta-analytic review. Sleep 2000;23:155-163.

15. Alward RR, Monk TH. A comparison of rotating-shift and permanent night nurses. Int J Nurs Stud 1990;27:297-302.

16. Karhula K, Hakola T, Koskinen A, Ojajärvi A, Kivimäki M, Härmä M. Permanent night workers' sleep and psychosocial factors in hospital work. A comparison to day and shift work. Chronobiol Int 2018:1-10.

17. Folkard S. Do permanent night workers show circadian adjustment? A review based on the endogenous melatonin rhythm. Chronobiol Int 2008; 25:215-224.

18. Bambra C, Whitehead M, Sowden A, Akers J, Petticrew M. "A hard day's night?" The effects of compressed working week interventions on the health and work-life balance of shift workers: a systematic review. $J$ Epidemiol Community Health 2008;62:764-777. 